\title{
Erratum to: Positive solutions of Schrödinger equations and fine regularity of boundary points
}

\section{Alano Ancona}

Published online: 24 April 2012

C) Springer-Verlag 2012

\section{Erratum to: Math. Z.}

DOI 10.1007/s00209-011-0940-5

There is a misleading typo in Theorem 1.1 statement (paper's second page). In (ii) the integral should be $\int_{\Omega} G\left(x_{0}, z\right) V(z) K_{y}^{V}(z) d z$ instead of $\int_{\Omega} G^{V}\left(x_{0}, z\right) V(z) K_{y}^{V}(z) d z$. Thus the correct statement is as follows.

Theorem 1.1 Let $V \in \mathcal{V}(\Omega, a)$. Given $y \in \partial \Omega$, the following are equivalent:

(i) The point $y$ is finely regular with respect to the potential $V$ in $\Omega$.

(ii) The integral $\int_{\Omega} G\left(x_{0}, z\right) V(z) K_{y}^{V}(z) d z$ is finite.

(iii) The integral $\int_{\Omega} G\left(x_{0}, z\right) V(z) K_{y}(z) d z$ is finite.

The online version of the original article can be found under doi:10.1007/s00209-011-0940-5.

\section{A. Ancona $(\bowtie)$}

Département de Mathématiques, Université Paris-Sud 11, 91405 Orsay, France

e-mail: alano.ancona@math.u-psud.fr 